\title{
Entrevista a Jaime Serra Puche*
}

\author{
Paz Consuelo Márquez-Padilla**
}

En el marco de los congresos y seminarios que han tenido lugar en la Universidad Nacional Autónoma de México, especialmente en el Centro de Investigaciones sobre América del Norte, a propósito de los veinte años de la firma del Tratado de Libre Comercio de América del Norte (TLCAN), entrevistamos al con el Dr. Jaime Serra Puche para discutir los logros y avances.

Paz Consuelo Márquez-Padilla (PCMP): El TLCAN marca el inicio de la apertura comercial, ¿cuál fue el ritmo de ésta en relación con otras aperturas?

Jaime Serra Puche (JSP): En realidad la apertura de nuestra economía inició cuando México entró al GaTT en 1986 y es muy importante que se sepa que nos tardamos cuarenta años en hacerlo. Obviamente los más avanzados estuvieron ahí desde el principio, pero incluso países subdesarrollados de América Latina entraron antes que nosotros. A partir de entonces ha habido una serie de eventos de apertura comercial, entre los cuales el tLCAN es uno de los más destacados. Con su puesta en vigor, por ejemplo, ha habido una recomposición del producto interno bruto (Рів) del país y se han establecido más relaciones comerciales con el resto del mundo, particularmente con América del Norte.

PCMP: En este contexto de crecimiento, ¿cuánto han aumentado las exportaciones de materias o productos diversos del petróleo?

\footnotetext{
* Jaime Serra Puche es presidente de SAI Derecho \& Economía y comparte la Presidencia del Consejo del Presidente sobre Actividades Internacionales en la Universidad de Yale, jsp@sai.com.mx.

** Investigadora del Centro de Investigaciones sobre América del Norte, UNAM, y directora de Norteamérica, <paz@unam.mx>.
} 
Antes del TLCAN, México era básica y predominantemente un exporta-

dor de petróleo. Hoy en día, a pesar de que el precio es muy elevado no representa más del 15 por ciento de las exportaciones totales del país. El 80 por ciento lo constituyen las manufacturas.
JSP: Éste es un punto importante. Antes de que nosotros entráramos al GATT, y naturalmente antes del TLCAN, México era básica y predominantemente un exportador de petróleo. Hoy en día, a pesar de que el precio es muy elevado no representan más del 15 por ciento de las exportaciones totales del país. El 80 por ciento lo constituyen las manufacturas, las cuales comenzaron a incrementarse de manera notable -incluso diría que espectacular - a partir de la entrada al TLCAN. Antes, México exportaba alrededor de cien millones de dólares en manufacturas diariamente, hoy exportamos mil millones de dólares.

PCMP: En el rubro de inversiones ¿cómo ha sido este proceso?

JSP: El TLCAN tiene un capítulo orientado a la inversión extranjera directa (IED). En promedio, antes de la entrada en el tratado, México recibía dos mil millones de dólares de IED al año, mientras que hoy, en promedio, recibe veinte mil millones de dólares.

PCMP: ¿Qué tendencia muestra la inversión extranjera en relación con los BRICs y cuáles son las perspectiva de México?

JSP: Es necesario subrayar la diferencia entre México y los BRICS, sobre todo con Brasil. La inversión atraída por México durante los veinte años del TLCAN, como porcentaje del PIB o del ingreso per cápita, es superior que en Brasil. En términos relativos, a nuestra producción y a nuestra población se ha atraído más inversión del exterior que la que han captado los brasileños. Ellos han experimentado un comportamiento de crecimiento diferente del de México que se explica por el crecimiento de China, pues al crecer tanto la economía del país asiático se generó una demanda de comodities, bienes de mercados de materias primas. Brasil es un importante exportador en este rubro y nosotros de manufacturas. En suma, estas condiciones permitieron a los brasileños crecer más que nosotros en términos económicos; sin embargo, ahora que China desacelera, los brasileños están bajando sus niveles de crecimiento mientras que nosotros seguimos creciendo. ${ }^{1}$

\footnotetext{
${ }^{1}$ En 2011, la economía china creció un 9.3 por ciento; la brasileña, un 2.7 por ciento, y la mexicana, un 4 por ciento. En 2012, China redujo su crecimiento al 7.7 por ciento, al igual que Brasil, que presentó un nivel del 1.1 por ciento, mientras que México se mantuvo en el 4 por ciento. Hacia 2013, China mantuvo el 7.7 por ciento, Brasil, el 2.5 por ciento y México bajó al 1.1 por ciento. Datos del Banco Mundial.
} 
PCMP: Seguimos debatiendo si existe o no una región de América del Norte realmente integrada, ¿considera que es así?

JSP: Ha habido un proceso de integración económica, no sé si a eso se refiera la pregunta. Ejemplo de ello son, primero, el crecimiento de los flujos comerciales (importaciones y exportaciones) en América del Norte, muy por encima de cómo crecieron en el resto del mundo; segundo, los ciclos económicos de Canadá, pero sobre todo los de Estados Unidos, se han ido coordinando con los de México; tercero, ha habido una convergencia macroeconómica donde Estados Unidos, Canadá y nosotros tenemos una inflación, tasas de interés y comportamiento del tipo de cambio parecidos, entre otras cuestiones. Hay una serie de indicadores económicos que muestran que, en efecto, la región se ha ido integrando y continuarán asemejándose los indicadores comunes.

PCMP: ¿Podemos afirmar que se ha generado un sistema de producción y comercialización compartidas?; ¿cómo responder a la crítica que señala la inexistencia de un valor agregado en estos sistemas compartidos?

JSP: Seguramente se trata de la cifra sobre la que hemos discutido durante estos meses en distintos eventos en torno a los veinte años del TLCAN. Tal cifra se refiere a que por cada dólar que México exporta aproximadamente cuarenta centavos corresponden a insumos de América del Norte, fundamentalmente de Estados Unidos. Asimismo, de cada dólar que exporta Canadá utiliza alrededor de veinticinco centavos. Por cada dólar de exportación de estas dos naciones, treinta y dos centavos, en promedio, corresponden a insumos provenientes de la región. Eso contrasta con lo que sucede con China, pues de cada dólar que exporta, cuatro centavos pertenecen a Estados Unidos. China es un ejemplo del modelo llamado outsourcing puro. El TLCAN es más un modelo de producción compartida. Ahora bien, ¿este contenido tan alto nos hace menos efectivos para crecer? La realidad es que nuestras exportaciones y su crecimiento desde que entró en vigor el tratado — que ha alcanzado hasta dos dígitos anuales- han sido los componentes más importantes de la demanda agregada. ${ }^{2}$ Empero, donde no hemos crecido tanto es en el consumo, el gasto gubernamental y el gasto privado, por lo tanto, han
Ha habido un proceso de integración económica, ejemplo de ello son, primero, el crecimiento de los flujos comerciales, segundo, los ciclos económicos de Canadá, tercero, ha habido una convergencia macroeconómica donde Estados Unidos, Canadá y nosotros tenemos una inflación, tasas de interés y comportamiento del tipo de cambio parecidos.

\footnotetext{
${ }^{2}$ En el periodo de 1994 a 1999, el crecimiento anual fue del 13.32 por ciento, aproximadamente y, en 2010, las exportaciones aumentaron al 20.5 por ciento, según información del Banco Mundial.
} 
sido otros los componentes de la demanda agregada que no han permitido que la economía mexicana crezca más.

PCMP: ¿Cómo están integradas las economías, específicamente en el sector manufacturero, y qué tan negativa es la síntesis de la economía mexicana con la estadunidense que no ha podido lograrse con otras naciones del mundo?

El Tratado no llevó a una mayor dependencia con Estados Unidos, pues al abrirse la economía hemos resultado competitivos para exportar a otras partes del mundo.
JSP: Como respuesta puedo darte otras cifras. La cantidad de exportaciones de México a Estados Unidos antes del TLCAN era mayor que hoy. Nuestro comercio con Estados Unidos no se ha concentrado más, sigue siendo altísimo, pero el tratado no llevó a una mayor dependencia con Estados Unidos, pues al abrirse la economía hemos resultado competitivos para exportar a otras partes del mundo.

PCMP: No obstante, la impresión que se tiene es la contraria.

JSP: La realidad es que el porcentaje de exportaciones hacia el mercado estadunidense era mayor en 1993 que en 2013, aunque, proporcionalmente, sigue siendo muy alto, cercano al 70 u 80 por ciento de las exportaciones mexicanas totales, y es natural, en virtud de la cercanía geográfica. Si eso es bueno o malo, es difícil determinarlo, lo cierto es que para que México pueda diversificar sus exportaciones llevándolas a otras partes del mundo es necesario que se integre con otras regiones y esto tiene que ver, en términos muy técnicos, con las reglas de origen. El TLCAN tiene ciertas exigencias basadas en reglas de origen, como que los productos y los insumos deben proceder de la propia región. Por ejemplo, si algún productor mexicano quiere exportar dentro de Norteamérica una mesa que fabricó, la madera utilizada debe provenir de alguno de los países del TLCAN; sin embargo, la misma mesa no cumpliría con las reglas de origen del acuerdo que tenemos con Europa si acaso la madera no proviene de México ni de ninguna región europea. Por ello resulta difícil para un productor exportar a Europa, pues no basta el canal comercial, debe ajustarse a las mencionadas reglas de origen, lo que afecta el proceso de manufactura, así como los lazos consolidados con ciertos mercados. Resulta indispensable para la diversificación de las exportaciones mexicanas la simplificación o eliminación de cuestiones vinculadas con reglas de origen. 
PCMP: Paradójicamente, dentro de la Unión Europea las reglas de origen permiten que las exportaciones sean más fáciles. Por tanto, dada la cantidad de tratados que México ha suscrito debe haber un cambio, tal como menciona, en dichas reglas.

JSP: La Unión Europea es de tipo aduanero, mientras que el TLCAN es un tratado comercial. La diferencia radica en que todos los países de la Unión Europea mantienen el mismo régimen comercial con el resto del mundo, mientras que en el TLCAN cada país mantiene sus propias reglas con el resto del mundo. Por eso se requiere de unas reglas de origen, que permitan dar un tratamiento preferencial a los productos de la región. La solución que podemos proyectar para el TLCAN es transitar del tratado comercial hacia una unión aduanera.

PCMP: Sería importante porque Estados Unidos y la Unión Europea están por efectuar un tratado en el que México quiere participar, pero no se le ha permitido. Deberíamos entrar como observadores, al menos para obtener ciertos beneficios.

JSP: Lo que me parecería mejor es que Norteamérica negociara con la Unión Europea como un todo por la siguiente razón: México ya tiene un tratado de libre comercio con Europa, los canadienses acaban de cerrar uno y Estados Unidos se encuentra en negociaciones. Si los tres países de América del Norte nos pusiéramos de acuerdo como región versus Europa todos resultaríamos beneficiados.

PCMP: ¿Qué tan factible sería pasar de una política de coordinación de políticas monetarias a una de corte fiscal y financiera?

JSP: Es más complicado. Ejemplo de ello es la crisis europea y se puede explicar porque tienen la misma moneda, pero no la misma disciplina monetaria y fiscal. No lo veo próximo en el TLCAN.

PCMP: ¿Cómo ha aumentado realmente la competitividad en América del Norte?
Lo que me parecería mejor es que Norteamérica negociara con la Unión Europea como un todo por la siguiente razón: si los tres países de América del Norte nos pusiéramos de acuerdo como región versus Europa todos resultaríamos beneficiados. 
México es el tercer país más competitivo en

la producción de manufacturas,

del mundo.

El primero es China y el segundo, India.

México tiene

una capacidad

de competir de manera importante en el mundo, y si además se le pide hacerlo con India o con China para

introducir sus manufacturas a

Estados Unidos resulta más competitivo en razón de la cercanía.
JSP: Hay un trabajo hecho por la firma $\mathrm{KPMG}{ }^{3}$ una compañía de contabilidad y finanzas, el cual demuestra que México es el tercer país más competitivo en la producción de manufacturas, del mundo. El primero es China y el segundo, India. México tiene una capacidad de competir de manera importante en el mundo, y si además se le pide hacerlo con India o con China para introducir sus manufacturas a Estados Unidos, resulta más competitivo en razón de la cercanía y sus consecuencias directas en el ámbito del transporte. Al proveer al mayor mercado del mundo, Estados Unidos, tenemos una ventaja sobre cualquier otro país, lo cual, obviamente, es un indicador de competitividad. El problema es que los estadunidenses y canadienses oscilan entre las posiciones diez y nueve en ese ranking de competitividad. Cuando los combinamos nos damos cuenta de que México es el que aporta mayores elementos de competitividad a la región y podríamos serlo mucho más si hubiera mucha más determinación sobre el futuro del TLCAN. Veamos, por ejemplo, el tema de la movilidad laboral: los estadunidenses la ven como un problema y se enfocan básicamente en las reglas migratorias para los mexicanos que están en su territorio y está bien. Creo que la regulación migratoria en Estados Unidos se debe adaptar para tratar mucho mejor a los mexicanos que están allá, quienes lo único que quieren es trabajar, ser decentes y tener una vida normal, aunque desafortunadamente los estadunidenses no lo han entendido así. Más bien, tendrían que verlo como una oportunidad, pues la pirámide demográfica estadunidense y canadiense está envejeciendo rápidamente, mientras que la nuestra no. Somos sus complementarios naturales en el mercado laboral. Si los estadunidenses pensaran en la movilidad laboral como una vía para aumentar la competitividad de su economía más que como un tema político, electoral, etcétera, que es como lo ven, la región podría alcanzar otros niveles de competitividad; sin embargo, no vislumbró un cambio en la perspectiva de este asunto en un corto plazo.

\footnotetext{
${ }^{3}$ El señalamiento de México como el más competitivo entre nueve países desarrollados fue publicado por KPMG en su guía de costos internacionales Alternativas competitivas 2012. Se basan en que nuestro país cuenta con el salario más barato, con un costo promedio de cuarenta y mil dólares anuales por empleado. Además de que ciertos sectores como las manufacturas, servicios corporativos, investigación y desarrollo, así como el de diseño digital, resultan el 21 por ciento más económicos que en Estados Unidos, aunque no tan baratos como en China e India (el 25.8 por ciento y el 25.3 por ciento más bajos respectivamente), pero la cercanía geográfica aligera la diferencia.
} 
PCMP: El tema demográfico adquirirá cada vez más importancia, pues la población de América del Norte, incluyendo a México, está envejeciendo y todos los países necesitarán población joven. La justificación para la creación del TLCAN fue que se pretendía exportar productos y no personas. ¿Qué opinión tiene al respecto?

JSP: Tenemos una ventaja demográfica para los próximos veinticinco años, comparados con Estados Unidos y Canadá. Por cierto también la tenemos sobre China, cuya pirámide poblacional está envejeciendo por la política que únicamente permite a las familias tener un hijo.

PCMP: Aunque, al parecer, han considerado cambiarla.

JSP: En efecto, pero sólo en casos especiales y de manera gradual, por lo que México continúa teniendo gran ventaja, pues puede ofrecer una fuerza laboral competitiva en la región, pero para ello debe cambiar el enfoque del tema migratorio. El panorama para la ley que se está discutiendo en el Congreso estadunidense no se ve claro: cómo resolver los problemas asociados con tener en su territorio a doce millones de migrantes indocumentados. Eso hay que resolverlo, está bien, pero también hay que ver qué sigue, que en mi opinión es la movilidad de mano de obra en la región del América del Norte incluido Canadá.

PCMP: ¿Por qué si se ha registrado este crecimiento de la economía, no se ha visto reflejado en los salarios, como sería de esperarse? Percibimos un mínimo cambio en las diferencias entre los países norteamericanos que esperábamos disminuyesen.

JSP: Hay que poner esto en número claros. Posiblemente la respuesta más importante a esa pregunta está en cómo comparan los salarios de las empresas exportadoras mexicanas con el promedio nacional, porque lo que promueve el TLCAN, y ésa era su intención original, son las exportaciones y la IED. Empecemos por establecer algunas cuestiones básicas: consideramos o definimos como exportadoras a las empresas que exportan más de la mitad de su producción. Es decir, si desplaza al exterior el 52 por ciento de su producción se le considera exportadora, pero no si desplaza el 32 por ciento, por ejemplo. Las exportadoras pagan sueldos y salarios un 30 por ciento superiores al promedio nacional. Las empresas
Tenemos

una ventaja demográfica para los próximos veinticinco años; comparado con Estados Unidos y Canadá [...] México [...] puede ofrecer una fuerza laboral competitiva en la región, pero para ello debe cambiar el enfoque del tema migratorio. 
con un componente alto de IED pagan sueldos y salarios así. El problema de la desigualdad no lo genera la actividad exportadora, existe porque muchos de los sectores tradicionales no se han modernizado, se han ido rezagando; además de que se enfrentan a cuestiones de monopolio y falta de competencia. Por ello, las empresas que se dedican a la exportación y con un contenido importante de IED están pagando mejor. Hay que pensar más bien por qué no han subido los salarios y los sueldos en las empresas o en los sectores que no se han abierto a la competencia, un ejemplo pueden ser las telecomunicaciones y la energía. En los sectores sobrerregulados o protegidos se paga menos y más en los no protegidos ni sobrerregulados, que además están compitiendo.

Los estadunidenses

han violado el TLCAN desde el día que entró en vigor, pues no dejaron pasar los camiones mexicanos a su territorio y como consecuencia nosotros tampoco dejamos entrar a los suyos.
PCMP: ¿Cómo ha crecido la competitividad en el transporte? Un tema difícil, sobre todo por los requerimientos de seguridad en la frontera a partir del 11 de septiembre.

JSP: Los estadunidenses han violado el TLCAN desde el día que entró en vigor, pues no dejaron pasar los camiones mexicanos a su territorio y como consecuencia nosotros tampoco dejamos entrar los suyos. Los primeros en cerrarse fueron ellos, pues el gobierno estadunidense, particularmente el Partido Demócrata, está sujeto a la presión de los Teamsters, el grupo que dirigía Jimmy Hoffa, por muchos considerado un gánsgter. Si desde el principio se hubiera cumplido la regla escrita en cuestión de transporte - ya son veinte años de ignorarla- el costo del transporte en América del Norte habría bajado enormemente. Aun así, sigue siendo menor que el de China. En la medida en que esta práctica estadunidense continúe, no mejorará la competitividad. Hemos aumentado la competitividad y eficiencia de nuestro transporte en territorio nacional y los estadunidenses en el suyo, pero en el momento de atravesar la frontera perdemos dinero y se paga un costo gigantesco. La clave está en que los estadunidenses cumplan con sus obligaciones en el TLCAN.

PCMP: Antes del tratado hubo muchas discusiones en torno al tema del ambiente, especialmente de Canadá. ¿Cómo entró este asunto al tratado?, ¿cuáles son sus percepciones sobre la situación ambiental en relación con China, nuestro gran competidor? 
JSP: El tema del ambiente entró al TLCAN cuando William Clinton, una vez electo presidente, exigió a México y Canadá establecer acuerdos laborales y ambientales, de lo contrario no mandaría el proyecto del tratado al Congreso. Acabábamos de hacer la negociación con el gobierno de George Bush Sr. y no queríamos volver a entrar en negociaciones. Por ello, en relación con estos temas se generaron tratados paralelos, pues fueron negociados, durante un año, en lo particular. Fue una labor compleja, pues los estadunidenses querían abolir toda la apertura prevista en el TLCAN a través de los asuntos ambientales y laborales. Por fortuna se negociaron bien y no se convirtieron en obstáculos al comercio. Sigue siendo un tema importantísimo y representa una ventaja de América del Norte sobre China. He hecho cálculos de la inversión que tendría que hacer Norteamérica para lograr la limpieza de partículas suspendidas, conocido como el escenario 450, y cuánto tendría que invertir China de su PIB: más del doble que nuestra región y por los próximos quince o veinte años. Esto quiere decir que tarde o temprano esos costos se verán reflejados en los precios de sus productos. $\mathrm{Al}$ invertir mucho menos seremos, nuevamente, más competitivos que los chinos.

PCMP: Muchas compañías ligadas al sector exportador han tenido un gran despegue; sin embargo, hubo otras tantas, en el mismo ámbito, que no lo lograron, con consecuencias tales como el cierre de empresas y despido de personal. Probablemente éste fue el origen del creciente sector informal de México. ¿Considera que esto ha propiciado diferencias regionales? Es decir, no es lo mismo hablar de los estados norteños, a los que les era mucho más fácil y económico exportar, que de los del Sur. ¿Son estos dos Méxicos de los que habla el informe McKinsey? ${ }^{4}$

JSP: ¿Cuáles fueron los sectores perdedores? Creo que enfocar el análisis desde los sectores no es correcto porque si uno analiza los veinte años del TLCAN, en un mismo sector hay empresas que ganaron y otras que perdieron. Entonces llegamos a la conclusión de que no hubo sectores per-

\footnotetext{
${ }^{4}$ Informe McKinsey \& Company, “A Tale of Two Mexicos: Growth and Prosperity in a Two Speedy Economy" marzo de 2014 en <http: / / www.mckinsey.com/insights / americas / a_tale_ of_two_mexicos $>$. Éste menciona que conviven dos tipos de empresas y escenarios empresariales, por un lado un sistema que crece rápidamente con competitivas multinacionales globales y plantas de última generación y, por el otro, un sistema de empresarios tradicionales mexicanos que no contribuyen al crecimiento. Cada uno se mueve en direcciones opuestas, pues la primera crece un 5.8 por ciento anualmente mientras que la otra cae el 6.5 por ciento por año.
}

He hecho cálculos de la inversión que tendría que hacer Norteamérica para lograr la limpieza de partículas suspendidas, y cuánto tendría que invertir China de su PIB: más del doble que nuestra región y por los próximos quince $o$ veinte años. Esto quiere decir que tarde o temprano esos costos se verán reflejados en los precios de sus productos. 
dedores sino empresas que no se supieron adaptar al proceso de apertura; unos se modernizaron...

PCMP: O no pudieron.

Sí ha habido empresas que han fracasado a lo largo de estos veinte años, pero mi impresión es que el efecto neto obró a favor de la creación de empleos y de mejores salarios en el sector exportador.
JSP: O no pudieron, efectivamente. Deben ser múltiples las explicaciones. Podemos preguntarnos, por ejemplo, si las empresas fracasaron por la apertura de la economía o porque no hubo una reacción a tiempo versus la modernización. Mi impresión es que ocurrió lo segundo. Muchas empresas, y eso lo constaté cuando fui secretario, no creían que se fuera a dar una apertura, que el TLCAN se materializaría o que México entraría al GATT. Entonces, cuando ocurrió, reaccionaron tardíamente. Sí ha habido empresas que han fracasado a lo largo de estos veinte años, pero mi impresión -si se ve el crecimiento de las exportaciones y el nivel de salarios de las empresas exportadoras- es que el efecto neto obró a favor de la creación de empleos y mejores salarios en el sector exportador. Hay que analizar qué pasa con las otras. Algunas tienen que pagar costos monopólicos por algunos de sus servicios, la energía es muy cara, etcétera, y se pueden sumar otros factores. Finalmente uno se da cuenta, como decíamos al principio de la entrevista, que son los sectores más regulados los que ven afectada su competitividad por estas condiciones y no por la apertura comercial. La cuestión regional es un tema mucho más estructural, es decir, las diferencias entre Chiapas y Nuevo León han existido con anterioridad al TLCAN. La pregunta es por qué el tratado no las resuelve. Era muy difícil que lo hiciera, particularmente porque se trataba de exportar a Estados Unidos y Canadá. En realidad, lo que debe resolverse es un tema de estructura nacional, no la apertura del mercado. Muchos de esos estados y sus regiones con un potencial económico importante están aislados. Mandar café desde Chiapas es mucho más costoso que mandar coches desde Hermosillo, por ejemplo. Estamos hablando de dos vocaciones naturales: para Chiapas el café y para Hermosillo los coches. El coste de transporte por la falta de infraestructura en el sur de México, en mi opinión, explica más que el hecho de que se haya abierto la economía. No hay que equivocar el diagnóstico y entonces concluir: "Los sectores del sur se quedaron atrás, entonces hay que cerrar la economía". No. Los estados del sur sí tienen problemas, pero la solución no es ésa, sino darles estructura: inversión, modernización, parques industriales, etcétera. 
PCMP: De todas las consecuencias negativas del TLCAN ¿cuál considera la menos prevista, que no se vio venir, y cuál el mayor beneficio que sobrepasó todas las expectativas?

JSP: Yo no sé cuántas sean las consecuencias negativas, me tendrían que dar un ejemplo.

PCMP: Algunas de las que se han señalado de la aplicación del tratado y la apertura económica que trajo consigo.

JSP: Creo que puedo mencionar algunos elementos que cambiaría del TLCAN, principalmente el tema de resolución de disputas. Lo haría mucho más estricto. Allí debimos haber hecho un esfuerzo mayor para que se consolidaran instituciones y reglas que obligaran a los países a cumplir los acuerdos a cualquier costo. El ejemplo de los camiones es uno de los más notorios. Se le dio una solución provisional. Se estableció un panel que determinó que Estados Unidos estaba violando el tratado, pero no se resolvió el problema estructuralmente, sólo se implantó un programa piloto al que se agregó el cobro de aranceles a los vinos estadunidense y otros productos. Pero, repito, no es una solución. Debe plantearse una respuesta de fondo que, por cierto, sería buena para todos. En lo que respecta a las consecuencias positivas, debo decir que son las exportaciones. Si me hubieran dicho que en veinte años exportaría mil millones de dólares en vez de cien habría respondido "estás loco", pero fue lo que ocurrió. 



\section{$\mathrm{ANEXO}$}

${ }^{1}$ Estas gráficas las presentó Jaime Serra Puche en el foro "El tLCAN a 20 años", organizado por Consejo Mexicano de Relaciones Internacionales (Comexi) en febrero de 2014. 



\section{EFECTOS SOBRE LA ECONOMÍA MEXICANA: ELIMINACIÓN DEL SESGO ANTIEXPORTADOR}

Conforme fue bajando el arancel aumentaron las exportaciones. Se muestra que ante el arancel efectivo promedio aumentaron drásticamente las exportaciones no petroleras.

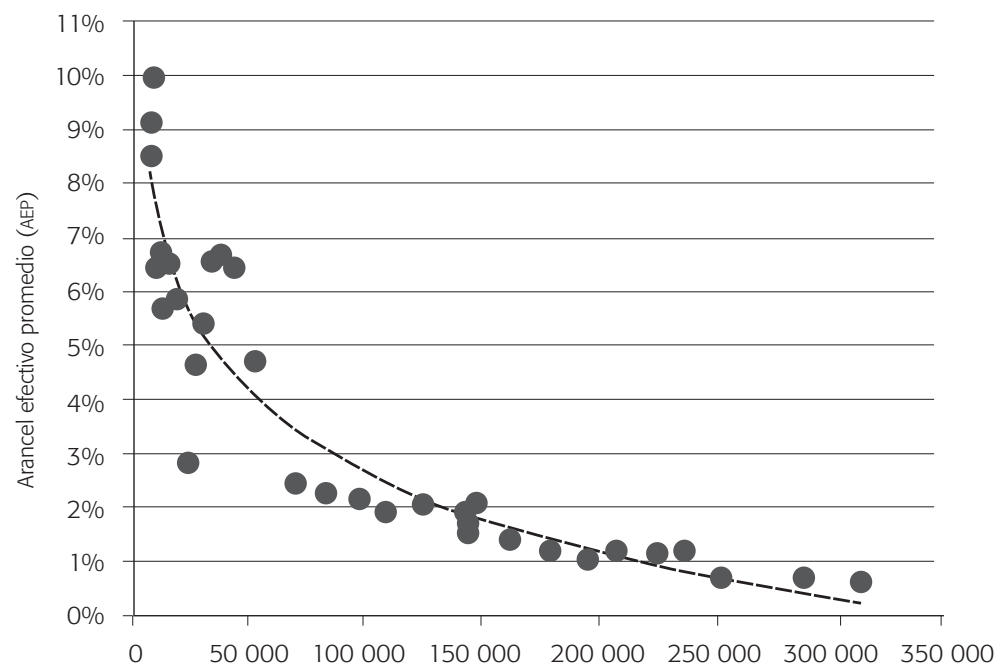

Exportaciones no petroleras (millones de USD)

REGRESIÓN DE MCO PARA EXPLICAR LAS EXPORTACIONES NO PETROLERAS (1981-2012)

Variable dependiente: variación anual de las exportaciones no petroleras de México

\section{Variable}

Var. anual del PIB de EUA

Var. anual del AEP de las importaciones

Variación anual del tipo de cambio peso/USD²

${ }^{1}$ El impacto del AEP en las exportaciones no petroleras es negativo y estadísticamente significativo.

2 La variación del tipo de cambio no es significativa para explicar la evolución de las exportaciones no petroleras.

Fuente: Análisis SAı Derecho \& Economía, con datos de Banco de México e INEGI. 


$$
M X_{X N P t}=\beta^{1} E A_{P I B t}+\beta_{2} M_{A E P t}+\beta_{3} T C_{t}+\varepsilon_{t}
$$

$M X_{X N P t}=$ Exportaciones no petroleras de México en $t$ (primera diferencia In).

$E U A_{P I B t}=$ PIB de Estados Unidos en $t$ (primera diferencia de In).

$M_{\text {AEPt }}=$ Arancel efectivo promedio (AEP) de importaciones en $t$ (primera diferencia de In).

$\mathrm{TC}_{\mathrm{t}}=$ Tipo de cambio peso/dólar en $t$ (primera diferencia de $\mathrm{In}$ ).

$\varepsilon_{\mathrm{t}}=$ Término de error en $t$.

\section{EFECTOS SOBRE LA ECONOMÍA MEXICANA: EXPORTACIONES}

A pesar de que México tiene un nivel más alto de exportaciones no petroleras per cápita, logró mantener una tendencia de crecimiento muy similar a los BRICS. Más aún, mostró un crecimiento de exportaciones muy por encima del crecimiento mundial.

\section{EXPORTACIONES NO PETROLERAS PER CÁPITA, BRICS VS. MÉXICO (dólares, 2000-2012)}

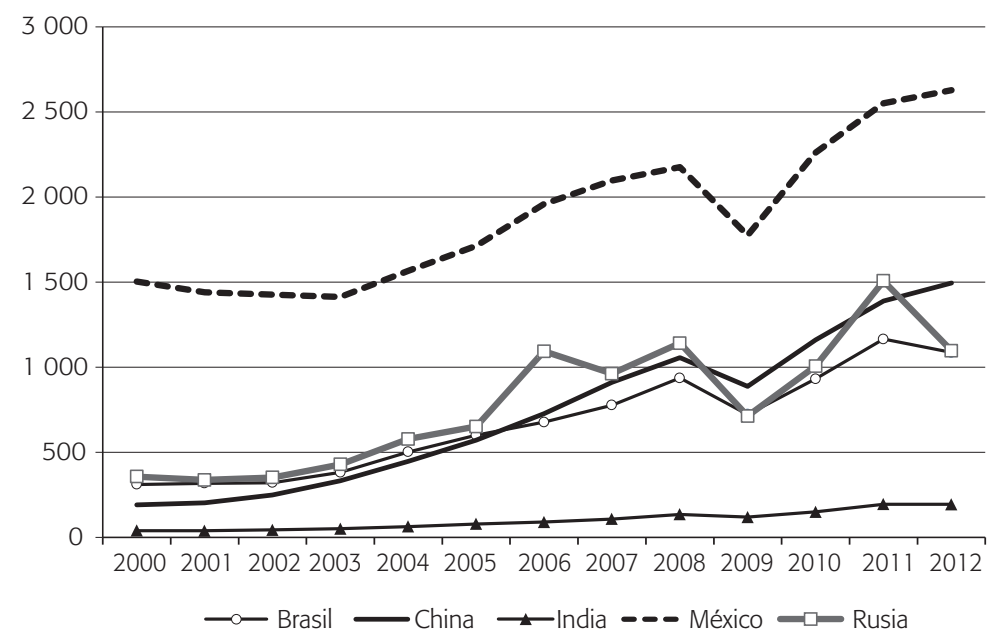


EXPORTACIONES NO PETROLERAS

(índice 1993=100, 1993-2012)

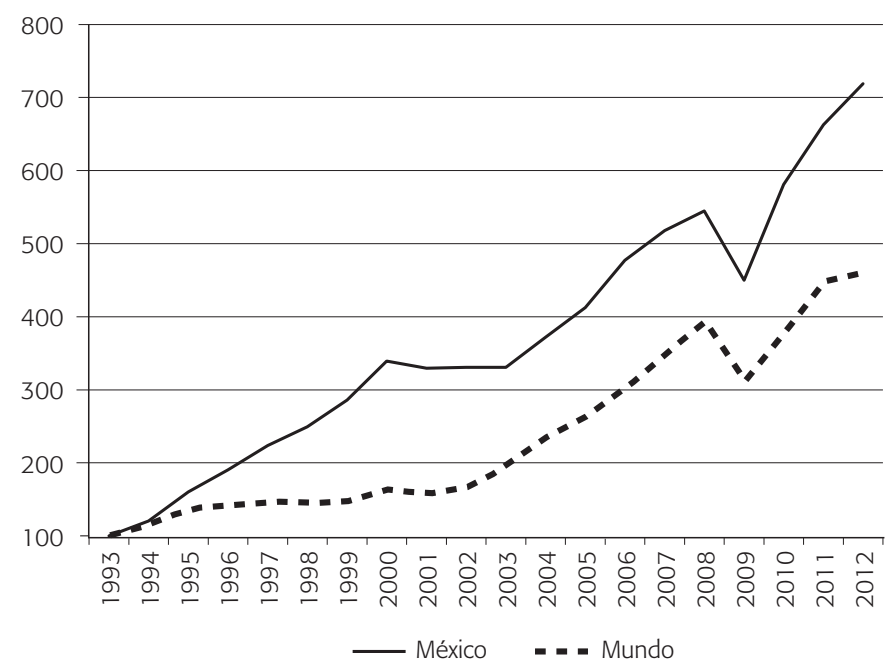

\begin{tabular}{|ccc|}
\hline & $\begin{array}{c}\text { EXPORTACIONES DIARIAS DE MÉXICO } \\
\text { (millones de dólares, 1993-2012) }\end{array}$ \\
Año & $\begin{array}{c}\text { Exportaciones } \\
\text { totales }\end{array}$ & $\begin{array}{c}\text { Exportaciones } \\
\text { no petroleras }\end{array}$ \\
1993 & 144 & 123 \\
2012 & 1030 & 883 \\
\hline
\end{tabular}

Fuente: Análisis sal Derecho \& Economía con datos del Banco Mundial. 
Esta gráfica ilustra que del total de exportaciones, la gran mayoría se integra por las del tipo manufacturero. Y que a pesar de que se han incrementado todos los componentes de la demanda agregada, el impacto de exportaciones sigue siendo mayor.

EXPORTACIONES PETROLERAS, MANUFACTURERAS Y TOTALES (millones de dólares, 1983-2013²)

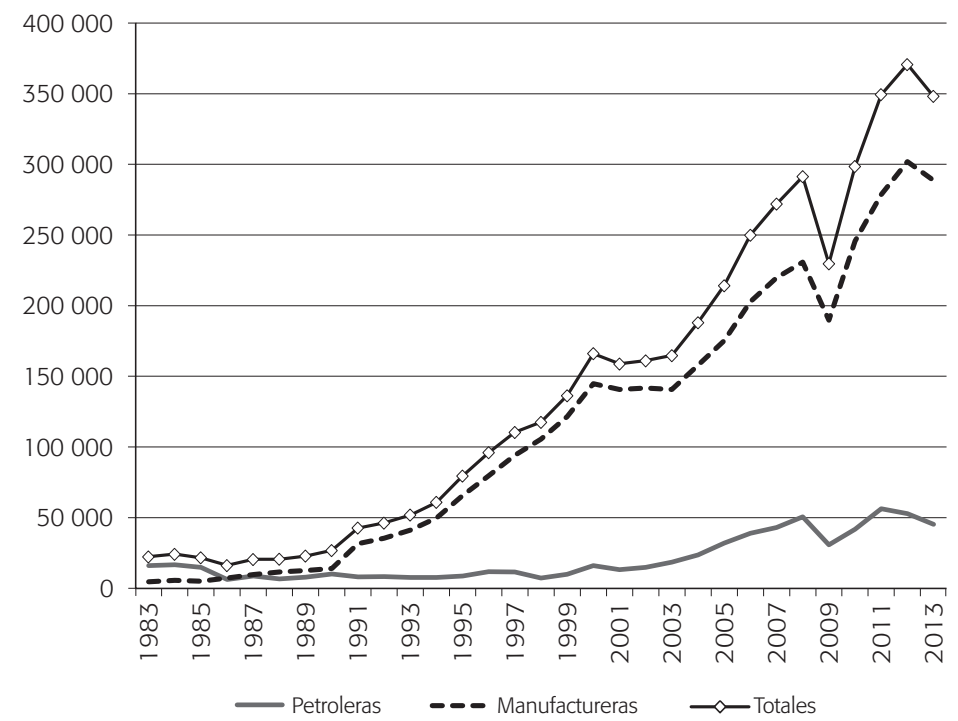

${ }^{1}$ Datos a noviembre de 2013. 


\section{COMPONENTES DE LA DEMANDA AGREGADA}

(indice $1992=100,1992-2012$ )

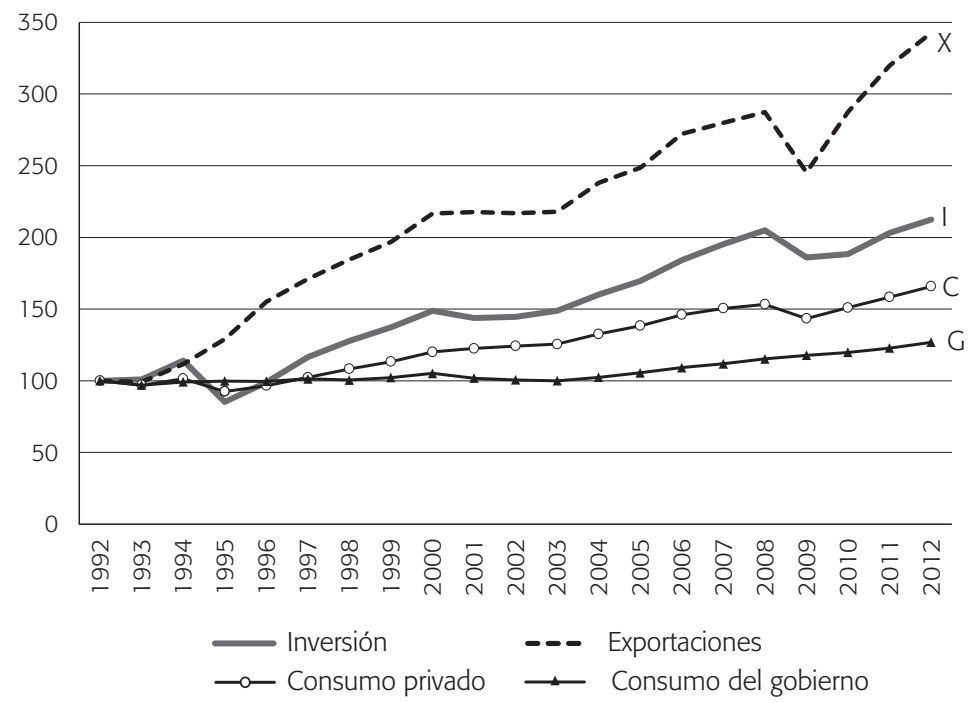

Fuente: Análisis SAI Derecho \& Economía con datos de INEGI. 
EFECTOS SOBRE LA ECONOMÍA MEXICANA:

INVERSIÓN EXTRANJERA

Aquí se muestra que hubo un rompimiento en la tendencia de la inversión extranjera directa con la entrada en vigor del TLCAN, al pasar de un promedio de 2900 MDD a uno de 19300 MDD.

\section{INVERSIÓN EXTRANJERA DIRECTA EN MÉXICO}

(miles de millones de dólares, 1993-2012)

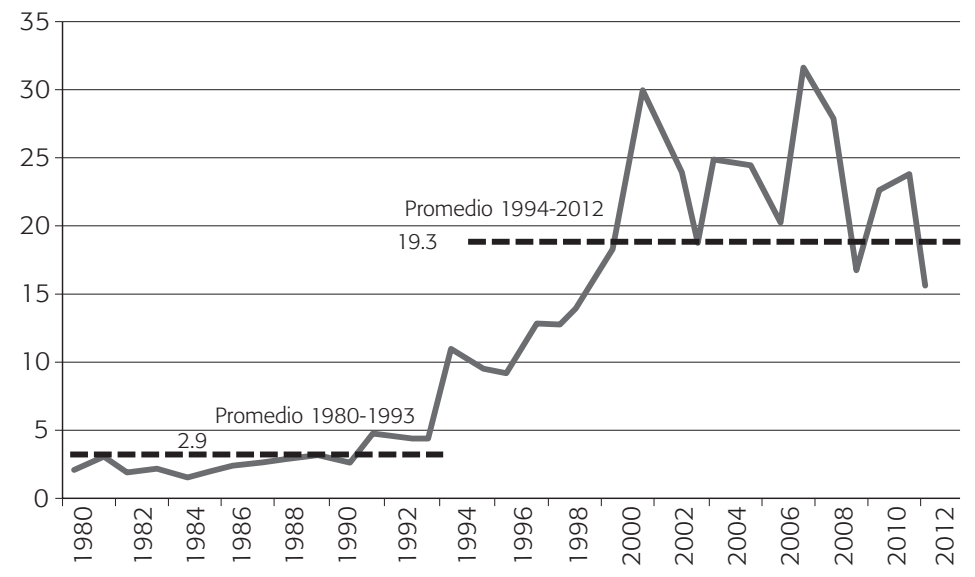

Fuente: Análisis SAI Derecho \& Economía con datos del INEGI. 
EFECTOS SOBRE LA ECONOMÍA MEXICANA:

IED (MÉXICO VS. BRICS)

IED COMO PORCENTAJE DEL PIB

(promedio móvil de porcentaje, 1988-2012)

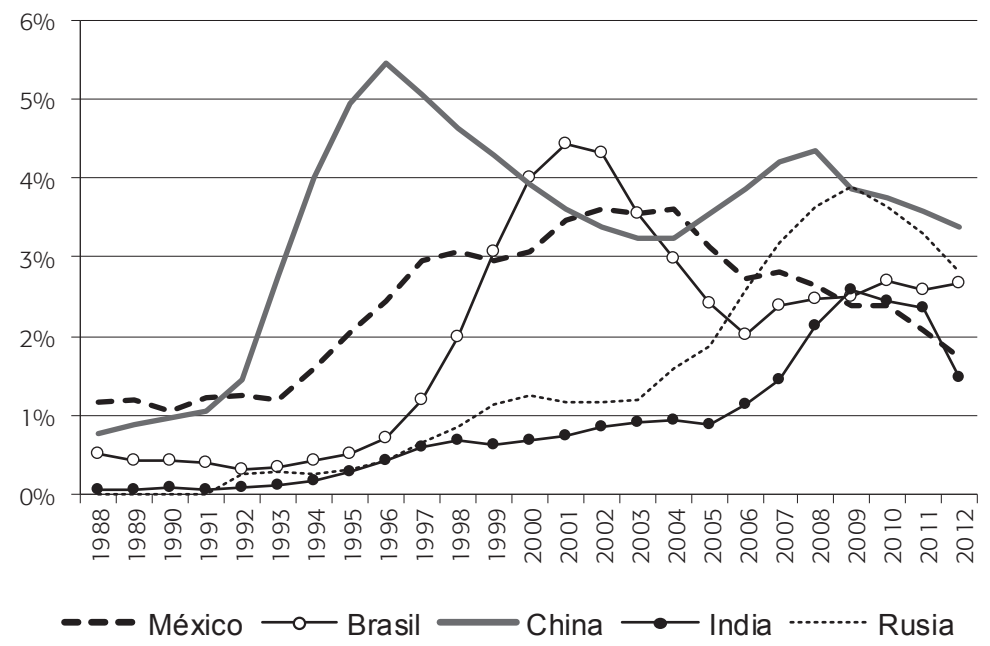

En general, se puede decir que el promedio de la IED de México como porcentaje del Producto Interno Bruto por país, fue menor que el de China.

\begin{tabular}{|lc|}
\hline \multicolumn{2}{|c|}{$\begin{array}{c}\text { IED COMO PORCENTAJE DEL PIB, PROMEDIO POR PAÍS } \\
\text { (porcentaje, 1994 2012) }\end{array}$} \\
País & $1994-2012$ \\
Brasil & $2.68 \%$ \\
China & $3.97 \%$ \\
India & $1.17 \%$ \\
Rusia & $2.03 \%$ \\
México & $2.78 \%$ \\
BRICs ${ }^{1}$ & $2.86 \%$ \\
\hline
\end{tabular}

1 Promedio ponderado.

Fuente: Análisis SAl Derecho \& Economía con información del Banco Mundial. 
EFECTOS SOBRE LA REGIÓN:

INTEGRACIÓN ECONÓMICA DE AMÉRICA DEL NORTE

SUBÍNDICE DE COMERCIO'

$($ TLCAN, 1988=100)

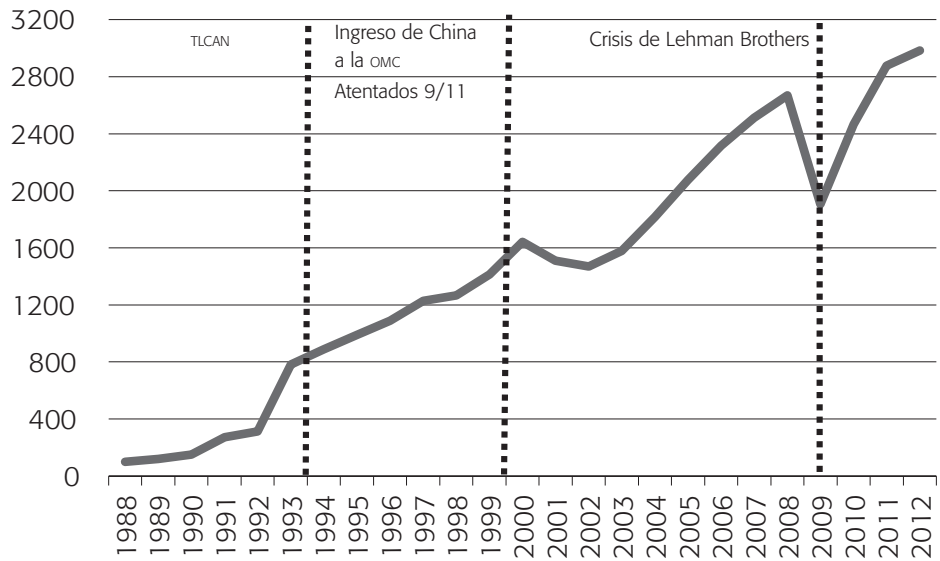

1 Subíndice de comercio: Índice del promedio ponderado de comercio (importaciones + exportaciones) entre Canadá, México y Estados Unidos.

\section{ÍNDICE DE INTEGRACIÓN COMERCIAL Y DE INVERSIÓN} (TLCAN, $1988=100)$

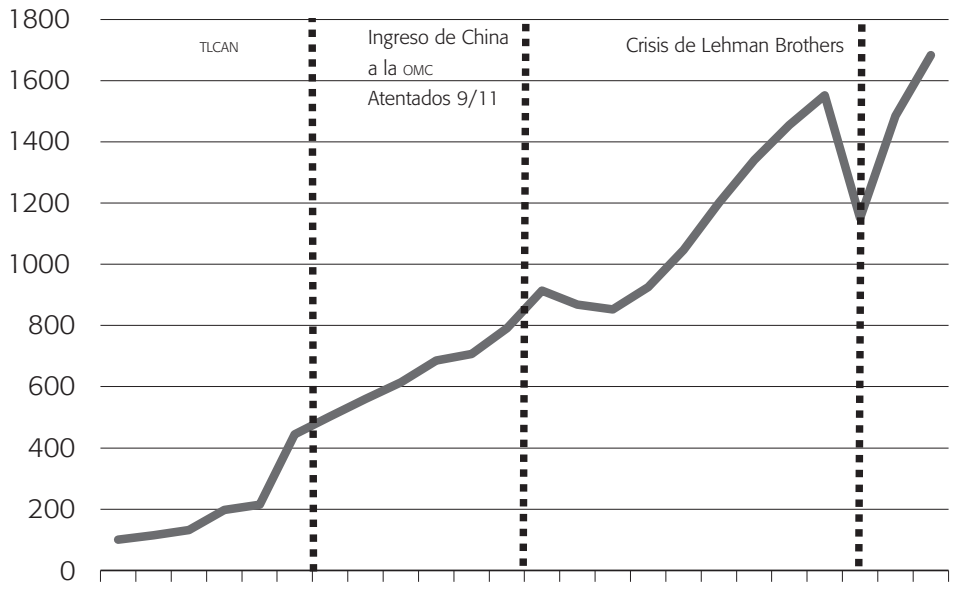

œ ஃ ৪ ন ন

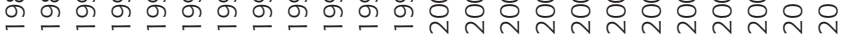

Aquí podemos observar que salvo en 2009 cuando tuvo lugar la crisis financiera de Lehman Brothers, hubo un constante aumento del comercio en la región entre Estados Unidos, México y Canadá, mismo que reinició una clara recuperación a partir del 2010. 
SUBÍNDICE DE IED'

(TLCAN, 1988=100)

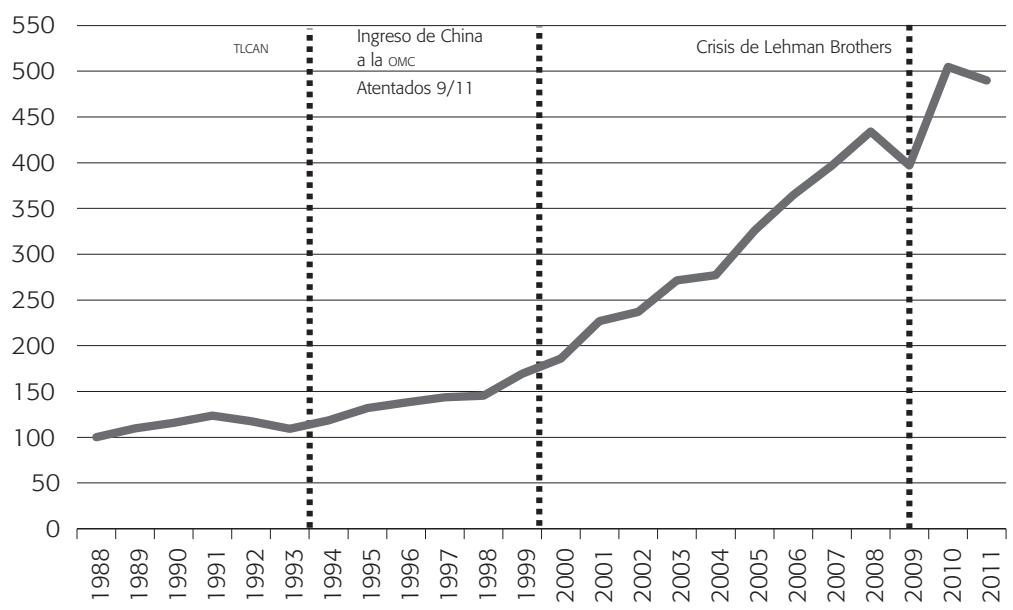

1 Subíndice de inversión: Índice del promedio ponderado de la inversión extranjera directa entre países del TLCAN.

Índice de integración: Promedio de los índices de inversión y comercio.

Fuente: Análisis SAI Derecho \& Economía con datos de INEGI, Banco de México, Secretaría de Economía, U.S. Census Bureau, BEA y Statistics of Canada.

En esta gráfica notamos que al ver el promedio ponderado de la inversión extranjera directa de los países del TLCAN, existe una clara tendencia de crecimiento. 
EFECTOS SOBRE LA REGIÓN:

CONVERGENCIA MACROECONÓMICA

VOLATILIDAD DEL TIPO DE CAMBIO

(desviación estándar, 1993-2012)

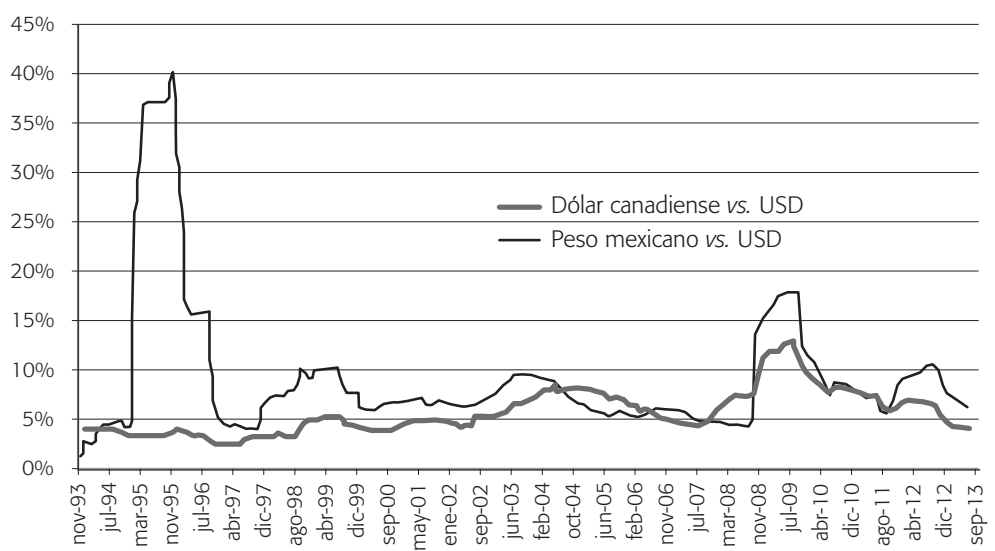

\begin{tabular}{|c|c|c|c|c|}
\hline \multicolumn{5}{|c|}{$\begin{array}{l}\text { PRUEBA DE COINTEGRACIÓN } \\
\text { (desviación estándar, enero de 1997-enero de 2014) }\end{array}$} \\
\hline \multicolumn{5}{|c|}{ Series: tipo de cambio vs. USD en México, Canadá y Estados Unidos } \\
\hline Eigenvalor & $\begin{array}{l}\text { Razón de } \\
\text { verosimilutud }\end{array}$ & $\begin{array}{l}\text { Valor crítico } \\
5 \%\end{array}$ & $\begin{array}{l}\text { Valor crítico } \\
\qquad 1 \%\end{array}$ & $\begin{array}{l}\text { Grado de } \\
\text { integración }\end{array}$ \\
\hline 0.009095 & 40.52835 & 15.49471 & 19.93711 & Ninguna ** \\
\hline 0.000184 & 0.801363 & 3.841466 & 6.634897 & A lo más 1 \\
\hline \multicolumn{5}{|c|}{$\begin{array}{l}\text { * denota el rechazo de la hipótesis nula con un nivel de significancia del 5\% } \\
\text { ** denota el rechazo de la hipótesis nula con un nivel de significancia del 1\% }\end{array}$} \\
\hline
\end{tabular}

Fuente: Análisis SAI Derecho \& Economía con datos del INEGI.

En esta gráfica observamos que existe una mayor tendencia en el peso y el dólar canadiense de comportarse como el dólar estadunidense, sobre todo a partir de 1997. 
FUTURO: COMPETITIVIDAD DE AMÉRICA DEL NORTE

\begin{tabular}{|c|c|c|c|c|c|c|}
\hline \multicolumn{7}{|c|}{$\begin{array}{c}\text { RENTABILIDAD DE LA INDUSTRIA POR PAÍS Y RANGO } \\
\text { (porcentaje, 2011) }\end{array}$} \\
\hline & Industria & México & China & India & EU & Canadá \\
\hline \multirow[t]{2}{*}{ Automotriz } & $\begin{array}{l}\text { Rentabilidad antes } \\
\text { de impuestos }\end{array}$ & $22.7 \%$ & $24.8 \%$ & $25.6 \%$ & $5.6 \%$ & $7.9 \%$ \\
\hline & Rango & 3 & 1 & 2 & 11 & 9 \\
\hline \multirow[t]{2}{*}{ Electrónica } & $\begin{array}{l}\text { Rentabilidad antes } \\
\text { de impuestos }\end{array}$ & $31.4 \%$ & $33.6 \%$ & $35.0 \%$ & $13.6 \%$ & $15.9 \%$ \\
\hline & Rango & 3 & 1 & 2 & 11 & 6 \\
\hline \multirow{2}{*}{$\begin{array}{l}\text { Manufactura } \\
\text { de precisión }\end{array}$} & $\begin{array}{l}\text { Rentabilidad antes } \\
\text { de impuestos }\end{array}$ & $19.3 \%$ & $22.5 \%$ & $22.6 \%$ & $3.5 \%$ & $6.2 \%$ \\
\hline & Rango & 3 & 1 & 2 & 11 & 7 \\
\hline \multirow{2}{*}{ Telecomunicaciones } & $\begin{array}{l}\text { Rentabilidad antes } \\
\text { s de impuestos }\end{array}$ & $29.0 \%$ & $31.4 \%$ & $32.7 \%$ & $6.5 \%$ & $9.7 \%$ \\
\hline & Rango & 3 & 1 & 2 & 11 & 7 \\
\hline \multirow[t]{2}{*}{ Aeroespacial } & $\begin{array}{l}\text { Rentabilidad antes } \\
\text { de impuestos }\end{array}$ & $28.1 \%$ & $30.8 \%$ & $32.5 \%$ & $7.9 \%$ & $10.1 \%$ \\
\hline & Rango & 3 & 1 & 2 & 11 & 7 \\
\hline \multirow[t]{2}{*}{ Agroalimentaria } & $\begin{array}{l}\text { Rentabilidad antes } \\
\text { de impuestos }\end{array}$ & $26.8 \%$ & $31.7 \%$ & $34.7 \%$ & $9.0 \%$ & $10.7 \%$ \\
\hline & Rango & 4 & 2 & 1 & 12 & 10 \\
\hline \multirow{2}{*}{$\begin{array}{l}\text { Productos } \\
\text { químicos }\end{array}$} & $\begin{array}{l}\text { Rentabilidad antes } \\
\text { de impuestos }\end{array}$ & $26.4 \%$ & $26.4 \%$ & $26.6 \%$ & $10.2 \%$ & $12.6 \%$ \\
\hline & Rango & 3 & 1 & 4 & 11 & 8 \\
\hline \multirow[t]{2}{*}{ Energía verde } & $\begin{array}{l}\text { Rentabilidad antes } \\
\text { de impuestos }\end{array}$ & $23.9 \%$ & $28.8 \%$ & $30.7 \%$ & $6.6 \%$ & $9.8 \%$ \\
\hline & Rango & 4 & 1 & 2 & 12 & 9 \\
\hline \multirow{2}{*}{$\begin{array}{l}\text { Dispositivos } \\
\text { médicos }\end{array}$} & $\begin{array}{l}\text { Rentabilidad antes } \\
\text { de impuestos }\end{array}$ & $38.8 \%$ & $42.7 \%$ & $46.2 \%$ & $8.5 \%$ & $11.2 \%$ \\
\hline & Rango & 3 & 1 & 2 & 11 & 9 \\
\hline \multirow{2}{*}{$\begin{array}{l}\text { Componentes } \\
\text { metálicos }\end{array}$} & $\begin{array}{l}\text { Rentabilidad antes } \\
\text { de impuestos }\end{array}$ & $32.8 \%$ & $37.3 \%$ & $40.2 \%$ & $8.1 \%$ & $11.4 \%$ \\
\hline & Rango & 3 & 2 & 1 & 12 & 10 \\
\hline \multirow[t]{2}{*}{ Farmaceútica } & $\begin{array}{l}\text { Rentabilidad antes } \\
\text { de impuestos }\end{array}$ & $34.0 \%$ & $38.0 \%$ & $39.8 \%$ & $10.6 \%$ & $13.2 \%$ \\
\hline & Rango & 3 & 1 & 2 & 11 & 8 \\
\hline \multirow[t]{2}{*}{ Plástica } & $\begin{array}{l}\text { Rentabilidad antes } \\
\text { de impuestos }\end{array}$ & $34.7 \%$ & $38.8 \%$ & $41.9 \%$ & $10.4 \%$ & $12.5 \%$ \\
\hline & Rango & 3 & 2 & 1 & 12 & 10 \\
\hline
\end{tabular}

Aquí se descubre que hay varias industrias en las que México es muy competitivo, particularmente la automotriz, la electrónica y la de telecomunicaciones. 